\title{
Impact of Students' Online Learning Burnout on Learning Performance - the Intermediary Role of Game Evaluation
}

\author{
https://doi.org/10.3991/ijet.v17i02.28555 \\ Dandan Mu, Wei Guo ${ }^{(\varpi)}$ \\ Hebei Jiaotong Vocational and Technical College, Shijiazhuang, China \\ guowei@hejtxy.edu.cn
}

\begin{abstract}
The rapid development of e-learning also highlights the phenomenon of students' learning burnout. Learning burnout will reduce students' sense of learning efficacy and academic achievement, and have a negative impact on their physical and mental health. As an auxiliary teaching method in recent years, game evaluation can effectively stimulate learning motivation, alleviate students' learning anxiety, and play an important role in alleviating students' network learning burnout. This study constructs a theoretical model of the impact of e-learning burnout on students' academic performance. In addition, the mediating effect of game assessment on students' e-learning burnout and academic achievement was measured. The results show that the questionnaire developed by Cronbach $\alpha$ The coefficient is 0.828 , indicating that the scale has high reliability. The kmo value is 0.781 , which means that the research data information is suitable for extracting information. Game evaluation has a significant mediating effect on Students' emotional exhaustion and low sense of achievement. The results of this study have positive reference value for exploring the influencing factors of e-learning burnout, deeply analyzing the causes of e-learning burnout, implementing the game of E-teaching, alleviating e-learning burnout and improving learning achievement.
\end{abstract}

Keywords-students, online learning, learning burnout, learning performance, gamification evaluation, mesomeric effect

\section{$1 \quad$ Introduction}

At present, China is vigorously developing the information technology industry. Thus, the application of information technology in education continues to affect the strategy and mode of teaching and learning. The efficient integration of information technology and university education and teaching can fundamentally change China's education industry. Under the background of the integration of information technology and education, online courses have gradually entered the field of learning and become an important way for learners to choose autonomous learning. Students' thoughts are open, active, and free, and their value orientation is more diversified and personalized. Online courses have attracted great attention in the field of higher edu- 
cation because of their high quality of curriculum resources, which breaks through the limitations of time and space and realizes the sharing of educational resources. Under the background of the epidemic, universities have also launched online courses with their own characteristics and students' favorite. However, the competition of online courses is fierce, and the development between regions and universities is seriously unbalanced, which makes various problems of online learning of students appear constantly. The teaching and learning effects of online courses have not achieved the desired results. The educational technology research field of online learning has gradually shifted from "resource construction" to "focusing on learning effect." It focuses on the evaluation of online course quality not only from the hardware construction of the course but also on learners' learning experience and learning performance level.

Online learning effectively uses online teaching resources, realizes the longdistance dissemination of knowledge, promotes the development of educational diversification and personalization, promotes the fairness of education, and enables learners to give full play to the characteristics of personalization and diversification. However, the separation of time and space between teachers and students and between students in online learning leads to the lack of close communication, interaction, and emotional support, which reduces the learning experience of students. Compared with traditional education, the online education industry is more likely to make students feel lonely, increase the learning load and psychological load, and significantly reduce the learning interest and motivation. This situation results in low online learning pass rate and low online learning performance of students. For some students, the learning burnout of online learning has become an important willingness to hinder their academic development and personality growth. Students' learning burnout refers to the students' aversion to learning in the process of online learning. Then, it shows their frustration, helplessness, and confusion in online learning. "Isolated" online learning is more likely to lead to students' learning burnout, and burnout greatly negatively impact learners' learning effect and physical and mental health. Through the introduction of game-based evaluation of online courses, especially game-based evaluation, the learning tasks are completed through role-playing, exploration, and collaborative competition. This way realizes students' comprehensive immersive experience of online learning courses, real-time information feedback between teachers and students, and timely interactive communication between peers. It also promotes students' knowledge transfer and skill mastery of online learning courses, reflects high-level thinking ability in analyzing and innovating more difficult problems, comprehensively alleviates learning burnout, and improves learning achievement.

\section{Theoretical basis and hypothesis presentation}

\section{$2.1 \quad$ Theoretical basis}

Maslow, A. H put forward Maslow's hierarchy of needs theory, which fully integrates motivation with humanistic psychology. He thinks that people's needs can be roughly divided into five levels [1]. The most important of them is the need of self- 
realization, which refers to the goal that people pursue infinitely. Students have motivation to learn for realizing their full value and potential in learning because of this pursuit. According to the hierarchy of needs theory, students fail to meet certain needs to a certain extent, which leads to the lack of learning motivation. Students cannot meet their basic needs in daily life; for example, insomnia cannot satisfy the need of normal rest, and disharmony with parents and friends cannot satisfy belonging and love. Teachers' indifference, neglect, and prejudice will not meet the needs of safety and respect, which will lead to students' inability to complete higher-level selfrealization satisfaction. Thus, the generation of students' internal motivation will be affected. Therefore, increasing enthusiasm and interest of students in online learning again and improving online learning performance of students are inseparable from the support of demand hierarchy theory.

Werbach, $\mathrm{K}$ argued that the game-based evaluation means organizing effective teaching activities through planned implementation [2]. It can further stimulate the psychological development potential of students, and the academic achievements obtained by the evaluation method are more in line with the educational objectives. Game evaluation adopts the principle of game teaching and highlights the integration of teaching curriculum and evaluation, which has become the mainstream trend of higher education teaching reform. Game evaluation is conducted in the daily life of students, which emphasizes the mutual integration and penetration between them. Teachers, as the main body of evaluation, should actively encourage the initiative and enthusiasm of students to participate in the evaluation activities, and they should be good at grasping the opportunity of evaluation to improve its validity and reliability. Teaching evaluation activities are conducted in the form of games. In the process of games, evaluation pays more attention to that the degree of students' investment in evaluation activities is close to the level in the real situation. Students' interest is constantly stimulated and their development is promoted through evaluation. It is conducive to the diversification of teacher evaluation methods. Teachers can design the game activities needed for evaluation and establish the depth and breadth of evaluation from their own ability. Thus, their potential as evaluators can be fully played. Teachers can conduct formative evaluation at any time and make appropriate responses to make it meet the needs of students' development for achieving the game point to the evaluation objectives. The evaluation and game processes are conducted nearly simultaneously, which brings the students in a perceptual and concrete situation and integrates the activity and evaluation.

\subsection{Hypothesis proposal}

"Learning burnout" is developed on the basis of the concept of "job burnout." At present, most learning burnout scales are also based on job burnout scales. In different industries, burnout psychology reflects different differences due to different occupational activity scenarios. Students' learning burnout reflects students' inactive learning mentality, which causes students' tired attitude and behavior toward learning due to the pressure of learning environment and low sense of self-efficacy. At present, the research scale put forward by Chinese scholar Lian Rong in 2005 is commonly used 
in China. This scale thinks that learning burnout is composed of three aspects: emotional exhaustion, improper behavior, and low sense of achievement. The internal consistency reliability test of the scale shows that the overall $\alpha$ coefficient is 0.865 , which shows that the "students' learning burnout scale" has good internal consistency reliability and structural validity [3].

With regard to the relationship between emotional exhaustion and job performance and between job performance and academic achievement, Gaines, J put forward the concept of emotional exhaustion [4]. The results showed that emotional exhaustion is partly the result of employees' personal characteristics, interpersonal environment, and work. Shyman, E conducted a sampling survey of 100 assistant educators [5]. The results showed that these educators have significant emotional exhaustion, which has a significant correlation with their work performance. Lee, Y. H completed an online questionnaire survey of 271 high school physical education teachers in the United States [6]. The results showed that a significant negative correlation exists between emotional exhaustion and job satisfaction. Hopman, J.A. found that emotional exhaustion increases with the occurrence of classroom disruptive behavior, which is consistent with the results of general education research [7]. Van den Berghe, L explored the relationship between emotional exhaustion and teaching motivation of 93 PE teachers [8]. The results showed that the emotional exhaustion of teachers is high when their autonomy motivation is low, and self-motivation may play a "buffer" role in the development of emotional exhaustion. R Richards, K. A investigated the relationship between teachers' emotional exhaustion and job satisfaction [9]. The research showed that schools should focus on improving the importance of teachers and reducing role stress and emotional exhaustion. The results of hierarchical regression analysis of Basim, H. N showed that all dimensions of emotional labor will affect emotional exhaustion [10]. Lee, Y. H argued that psychological resilience is negatively correlated with emotional failure, and emotional failure is positively correlated with turnover intention [11]. Ansari, A found that the interaction between teachers and students in class and the teaching effect are lower when teachers have more emotional exhaustion [12]. Platsidou, M thought that emotional exhaustion can be predicted by satisfaction with the job and major subscales [13]. Emotional exhaustion leads to teachers' job burnout and reduces job satisfaction. On the basis of the previous studies, this study holds that, in the process of online learning for students, students are prone to emotional exhaustion after the novelty of accepting online learning gradually recedes due to the lack of good interaction in online learning and the simplification of learning tasks. This situation leads to the poor learning state of students, and negative emotions accompanied by a series of evasive behaviors are not conducive for learners to learn. Therefore, this study puts forward hypothesis $\mathrm{H} 1$.

H1: Emotional exhaustion will significantly negatively affect students' online learning performance.

For the relationship between misconduct and academic achievement, Cothran, D.J. thought that differences exist in gender, grade, and ethnic background in students' poor behaviors in physical education class [14]. Cothran, D.J. found that students' improper behavior will negatively impact class time, content, and attitude [15]. Finn, J.D. obtained that poor behaviors are related to high school grades, test scores, gradu- 
ation rates, and dropout rates [16]. Students with good behaviors are more likely to receive higher education than students with moderate behaviors. Gregory, J.F. analyzed three specific responses of school students to children's poor behaviors [17], and the results showed that students with improper behaviors are more likely to have weariness of school and drop out of school. Hsu, W.T. analyzed the manifestations of students' poor behaviors in physical education, and the results showed an obvious negative correlation between sports achievements and improper behaviors [18], which can be adjusted by moral alienation. Ö ZEK, U investigated the impact of score retention on the incorrect behavior of students in Florida [19]. The research showed that improper behavior will increase the possibility of repetition. Supaporn, S believed that high school students' misconduct will reduce their learning enthusiasm and reduce their academic performance [20]. Supaporn, S also believed that the vague and incomplete teaching tasks of physical education teachers will lead to improper behavior of students participating in teaching, and then, it will reduce students' physical education performance [21]. Glock, S argued that teachers' sensitivity to students' gender bias impacts students' misconduct and will reduce their academic performance [22]. Ratcliff, N.J. found that the interaction between teachers and students on teaching issues can increase students' time spent on study, and students' misconduct will affect teachers' classroom scores [23]. Therefore, given that online learning separates teachers and students in space, it cannot ensure that teachers treat each student objectively and fairly to a certain extent. The online learning platform does not realize real-time supervision and feedback on students' real learning situation. Thus, students can easily have various improper behaviors without teachers' supervision, such as hanging up, speeding up learning progress, looking for someone to replace learning, and other situations. Thus, students do not conduct efficient knowledge learning. Therefore, this study proposes hypothesis $\mathrm{H} 2$.

$\mathrm{H} 2$ : Improper behavior will significantly negatively affect the online learning performance of students.

With regard to the relationship between low sense of achievement and academic achievement, Ford, D. Y found that students with low sense of achievement also show very obvious dyslexia [24]. Marks, G. N obtained that low sense of achievement greatly reduces students' chances of completing their studies and entering college [25]. Lalley, J. P analyzed the effectiveness of third grade mathematics achievement and academic self-concept [26]. The results showed that students with high sense of achievement have significantly improved in mathematics concept, mathematics problem, and mathematics calculation. Gilleece, L showed significant gender differences in the distribution of high and low achievers, and the low achievers have more emotions of planning to leave early [27]. Wey, G. L argued that the main reason for the low academic performance of children with cleft palate is the persistent low sense of accomplishment [28]. Espinosa, R (1986) mentioned that students with low sense of accomplishment will also have lower reading and math scores than students with high sense of accomplishment [29]. Merrell, K. W showed that students with low sense of achievement have lower self-restraint behavior, which will affect their academic performance [30]. Kingdon, G believed that low achievement has a certain negative impact on the achievements of students [31]. In summary, a reverse correlation exists 
between students' low sense of achievement and their academic performance. However, the low sense of achievement is influenced by many factors, such as family education, psychological state, self-esteem, and personality quality. The students' sense of local achievement is stronger when the online education time is longer, which makes their academic performance tend to decrease gradually with time. Therefore, this study puts forward hypothesis H3.

H3: Low sense of achievement will significantly negatively affect students' online learning performance.

Game evaluation can fully stimulate students' online learning motivation and improve learning effect. Game elements summarized by game evaluation can make students experience more pleasant and improve their emotional experience and interactive friendliness in the process of lonely and helpless online learning. Game-based evaluation can stimulate students' learning motivation and provide academic achievements more than traditional paper-based evaluation. On the relationship between gamification evaluation and academic achievement, Yu, W.F. showed that network-based problem-solving teaching may improve and maintain learners' problem-solving skills in a long time. Lu, S. J showed that the scores of AR group are significantly higher than those of the control group [32-33], which indicates that AR technology can significantly promote learners' motivation and academic achievement. Hieftje, K obtained that the video game "knowledge war" based on Educational Mathematics tablet has an obvious positive impact on mathematics achievement and self-ability [34], especially for students with low mathematics skills. Kocadere, S.A. believed that gamification evaluation can trigger the happiness, motivation, mobility, and learning of students, and it can promote the learning effect [35]. Yildirim, I found that game-based teaching practice positively impacts students' achievement and attitude toward curriculum [36]. Ylrm, also demonstrated the influence of gamification on students' academic achievements through meta-analysis [37], and the results showed that gamification increases the positive value of academic achievements by $7.2 \%$. Leaning, $\mathrm{M}$ analyzed the effectiveness of exploring game technology, the concept of gamification, and its application in education [38]. Dias, J found that gamification has been successfully applied in some educational environments, and gamification evaluation has increased students' classroom participation rate [39]. G ö KS ü n, D. O found that the application of game-based activities by testing can improve students' enthusiasm for classroom participation the next day. Therefore, this study proposes hypotheses $\mathrm{H} 4, \mathrm{H} 5$, and $\mathrm{H} 6$ [40].

H4: Game evaluation significantly negatively impacts students' online learning performance in emotional exhaustion and has a significant mediating effect.

H5: Game evaluation significantly negatively impacts students' online learning performance in improper behavior and has an obvious intermediary effect.

H6: Game evaluation significantly negatively impacts students' online learning performance with low sense of accomplishment and has a significant mediating effect. 


\section{$3 \quad$ Research design}

\subsection{Measuring tools}

The scale design of this study includes three parts, with 32 questions. The first part is the basic information of the respondents. Four questions involve gender, grade, discipline, and understanding of gamification evaluation. The second part covers three factors of learning burnout. This study uses the scale proposed by Lian Rong and other scholars. The scale consists of 8 items of emotional depression, 6 items of misbehavior, and 6 items of low achievement, with 3 dimensions and 20 items. It has good internal consistency, reliability, and structural validity. The third part includes 8 questions, including 5 questions on learning performance and 3 questions on game evaluation. The scoring method of this research scale adopts Likert's five-point scoring method, and the coincidence degree is divided into five grades, namely, very inconsistent, comparatively inconsistent, general, very consistent, and comparatively consistent, with corresponding scores ranging from 1 to 5 .

\subsection{Research object}

In this study, students in a 985 university in Jiangsu Province were selected as the research objects, and 186 students were distributed the students' learning burnout scale developed by this study by random sampling method. At the same time, the research objects were informed that this survey was only for scientific research, and the respondents were asked to fill the questionnaire according to the real situation in an anonymous way. After scientific screening and elimination of invalid questionnaires, 148 valid questionnaires were obtained, and the effective recovery rate was $79.57 \%$. This study involved 86 girls $(58.11 \%)$ and 62 boys (41.89\%); 67 in Liberal Arts (45.27\%), 53 in Science (35.81\%), and 28 in Engineering (18.92\%); 42 in grade one (28.38\%), 39 in grade two (26.35\%), 47 in grade three (31.76\%), and 20 in grade four (13.51\%); $84(56.76 \%)$ knew about gamification evaluation and $64(43.24 \%) \mathrm{did}$ not know gamification evaluation.

\section{$4 \quad$ Result analysis}

\subsection{Reliability and validity analysis}

Reliability analysis considers the consistency or stability of research results, that is, reliability analysis. Internal reliability mainly analyzes whether a group of items test the same content, which is the consideration of internal consistency. The commonly used coefficient is Cronbach's $\alpha$ coefficient. The reliability is higher when Cronbach's $\alpha$ coefficient is higher, which indicates that the error of the questionnaire test results is small. In general, if Cronbach's $\alpha$ coefficient is greater than 0.7, then the reliability is high; if it is greater than 0.9 , then the scale has high internal reliability. 
As shown in Table 1, the overall Cronbach's $\alpha$ coefficient in this study is 0.828 . The Cronbach's coefficients of all variables are greater than 0.7 , which implies that the internal consistency reliability of the scale in each dimension is good or very good. In other words, the scale has high reliability.

Table 1. Reliability test results

\begin{tabular}{|c|c|c|c|c|c|}
\hline Variable & $\begin{array}{l}\text { Question } \\
\text { options }\end{array}$ & \begin{tabular}{|c|}
$\begin{array}{c}\text { Total correlation of } \\
\text { correction items } \\
\text { (CITC) }\end{array}$ \\
\end{tabular} & $\begin{array}{c}\text { The alpha factor of } \\
\text { the item has been } \\
\text { deleted }\end{array}$ & $\begin{array}{c}\text { Cronbach alpha } \\
\text { coefficient }\end{array}$ & \begin{tabular}{|c|}
$\begin{array}{c}\text { Cronbach } \\
\text { alpha } \\
\text { coefficient }\end{array}$ \\
\end{tabular} \\
\hline \multirow{8}{*}{$\begin{array}{l}\text { Be down in spirits } \\
\text { (Factor1) }\end{array}$} & A1 & 0.560 & 0.740 & \multirow{8}{*}{0.777} & \multirow{28}{*}{0.828} \\
\hline & $\mathrm{A} 2$ & 0.648 & 0.726 & & \\
\hline & $\mathrm{A} 3$ & 0.752 & 0.717 & & \\
\hline & A4 & 0.605 & 0.747 & & \\
\hline & A5 & 0.545 & 0.741 & & \\
\hline & A6 & 0.511 & 0.747 & & \\
\hline & A7 & 0.360 & 0.783 & & \\
\hline & A8 & 0.129 & 0.813 & & \\
\hline \multirow{6}{*}{$\begin{array}{l}\text { Improper behav- } \\
\text { ior } \\
\text { (Factor2) }\end{array}$} & B1 & 0.447 & 0.659 & \multirow{6}{*}{0.703} & \\
\hline & B2 & 0.435 & 0.663 & & \\
\hline & B3 & 0.624 & 0.604 & & \\
\hline & B4 & 0.613 & 0.598 & & \\
\hline & B5 & 0.275 & 0.722 & & \\
\hline & B6 & 0.254 & 0.711 & & \\
\hline \multirow{6}{*}{$\begin{array}{l}\text { Low sense of } \\
\text { accomplishment } \\
\text { (Factor3) }\end{array}$} & $\mathrm{C} 1$ & 0.496 & 0.827 & \multirow{6}{*}{0.834} & \\
\hline & $\mathrm{C} 2$ & 0.554 & 0.817 & & \\
\hline & $\mathrm{C} 3$ & 0.740 & 0.777 & & \\
\hline & $\mathrm{C} 4$ & 0.633 & 0.801 & & \\
\hline & $\mathrm{C} 5$ & 0.719 & 0.782 & & \\
\hline & C6 & 0.510 & 0.828 & & \\
\hline \multirow{5}{*}{$\begin{array}{l}\text { Learning perfor- } \\
\text { mance } \\
\text { (Factor4) }\end{array}$} & D1 & 0.584 & 0.869 & \multirow{5}{*}{0.868} & \\
\hline & D2 & 0.704 & 0.836 & & \\
\hline & D3 & 0.703 & 0.840 & & \\
\hline & D4 & 0.719 & 0.833 & & \\
\hline & D5 & 0.771 & 0.819 & & \\
\hline \multirow{3}{*}{$\begin{array}{l}\text { Gamification } \\
\text { evaluation. } \\
\text { (Factor5) }\end{array}$} & E1 & 0.723 & 0.848 & \multirow{3}{*}{0.872} & \\
\hline & E2 & 0.783 & 0.794 & & \\
\hline & E3 & 0.759 & 0.816 & & \\
\hline
\end{tabular}

Validity analysis measures the accuracy and effectiveness of scale items, which mainly involve the generalization of scale and represent the effectiveness of scale. This study focuses on content validity and structural validity. Content validity refers to the degree to which the designed items can represent the measured content, that is, the representativeness and suitability of the questionnaire items. The questionnaire on 
online learning burnout and its influencing factors in this study is obtained on the basis of considerable literature and has a good theoretical basis.

In this study, KMO and Bartlett's tests are used to verify the validity. Table 2 shows that the KMO value is 0.781 , which is ranging from 0.7 to 0.8 . Research data information is also suitable for extracting information.

Table 2. Results of validity analysis

\begin{tabular}{|l|c|c|}
\hline Kmo value & 0.781 \\
\hline \multirow{3}{*}{ Bartlett sphericity test } & Approximate chi square & 2109.334 \\
\cline { 2 - 3 } & $\mathrm{df}$ & 378 \\
\cline { 2 - 3 } & $\mathrm{P}$ value & 0 \\
\hline
\end{tabular}

Table 3 shows that the AVE square root value of factor 2 is 0.573 , which is less than the maximum value of absolute value of correlation coefficient between factors. In other words, its discrimination validity is not good. The AVE square root value of other factors is greater than the maximum value of absolute value of correlation coefficient between factors. Therefore, the scale has good discrimination validity. Overall, the discrimination validity of the scale is good.

Table 3. Discriminant validity: Pearson correlation and square root of AVE

\begin{tabular}{|l|c|c|c|c|c|}
\hline & Factor1 & Factor2 & Factor3 & Factor4 & Factor5 \\
\hline Factor1 & 0.594 & - & - & - & - \\
\hline Factor2 & 0.102 & 0.573 & - & - & - \\
\hline Factor3 & 0.255 & 0.644 & 0.692 & - & - \\
\hline Factor4 & 0.069 & 0.368 & 0.315 & 0.758 & - \\
\hline Factor5 & 0.005 & -0.212 & -0.043 & 0.029 & 0.835 \\
\hline
\end{tabular}

The following results are obtained from Table 4.

Suppose $\mathrm{H} 1$ holds, that is, emotional exhaustion will significantly negatively affect the online learning performance of students. At the significance level of $1 \%$, a significant negative correlation exists between emotional exhaustion and academic achievement. This conclusion is consistent with the conclusions of most studies. The reason is mainly due to that some students are affected by the epidemic. Many universities are also not allowed to adopt online learning methods. Thus, some students have a large psychological gap, lack self-confidence, or are not interested in the knowledge content of online learning without quickly adapting to the online learning methods. This conclusion also enlightens us that Chinese universities, as the main unit of online teaching, should pay attention to improving teachers' teaching methods in online teaching, pay close attention to students' psychological changes, give guidance to students' online learning methods, and comprehensively improve online teaching efficiency and students' learning performance.

Suppose $\mathrm{H} 2$ holds, that is, improper behavior will significantly negatively affect the online learning performance of students. At the significance level of $1 \%$, a significant negative correlation exists between improper behavior and academic achieve- 
ment, which is consistent with the existing research. The main reason is that students cannot be supervised by teachers in real time during the online teaching process. Some students also do not have good self-control ability. At the same time, they are tired of learning, which results in behaviors, such as skipping classes, not listening to lectures, being late, leaving early, and not handing in homework. Given the popularization of higher education in China, many students have difficultly adapting to the autonomous learning mode in the university stage as well after coming out of the heavy learning atmosphere in high school. They have not formed a good and scientific learning mode, and they still stay in the mechanical memory learning mode in high school. This situation results in low efficiency and poor performance of online learning.

Suppose $\mathrm{H} 3$ holds, that is, low sense of accomplishment will significantly negatively affect the online learning performance of students. At the significance level of $1 \%$, a significant negative correlation exists between low sense of accomplishment and academic achievement, which is consistent with the conclusions of most studies. The reason is that students with low sense of accomplishment will have fear of difficulties, escape psychology, have low learning efficiency, and lack the ability to resist setbacks. At the same time, students pay more attention to the study of professional knowledge and lack psychological education. Thus, they have difficulty obtaining a sense of achievement and positive feedback from learning activities and motivation after completing learning tasks, which results in learning burnout. Students with low academic performance rely too much on teachers. Considering the lack of teacher guidance in online teaching, students easily release themselves, indulge in the network, cannot concentrate on their study, and have reduced academic performance.

Table 4. Regression results

\begin{tabular}{|l|c|c|c|}
\hline & Regression coefficient & $\mathbf{9 5 \%}$ CI & VIF \\
\hline Constant & $5.859^{* *}(16.874)$ & $5.178 \sim 6.539$ & - \\
\hline Factor1 & $-0.233^{* *}(-2.925)$ & $-0.390 \sim-0.077$ & 1.185 \\
\hline Factor2 & $-0.263^{* *}(-3.344)$ & $-0.417 \sim-0.109$ & 1.314 \\
\hline Factor3 & $-0.407^{* *}(-5.274)$ & $-0.558 \sim-0.256$ & 1.264 \\
\hline Sample size & \multicolumn{3}{|c|}{0.409} \\
\hline $\mathrm{R}^{2}$ & \multicolumn{3}{|c|}{0.397} \\
\hline Adjust $\mathrm{R}^{2}$ & \multicolumn{3}{|c|}{$\mathrm{F} \mathrm{(3,144)=33.204, \textrm {p } = 0 . 0 0 0}$} \\
\hline F value & \multicolumn{3}{|c|}{} \\
\hline
\end{tabular}

D-W value: $1.683,{ }^{*} \mathrm{P}<0.05^{* *} \mathrm{P}<0.01$, t value in brackets

H4 and H6 are assumed to be true and H5 is assumed to be not true in Table 5. That is, game evaluation has a significant mediating effect on students' online learning performance in emotional exhaustion and low sense of achievement. The main reason is that the game evaluation method can transform the online learning process from simple teacher evaluation to game evaluation system. Students can more actively participate in teaching evaluation by using the existing game teaching system to conduct interesting exercises before class and providing timely feedback in class and knowledge quiz after class for students' online learning. This way can alleviate their 
emotional exhaustion and improve their sense of learning achievement. The characteristics of online gamification evaluation are also brought into full play in this way. Thus, students can take the initiative to participate in online tests, which alleviates students' online learning burnout. After-school gamification evaluation accelerates students' online learning progress and learning quality. Integrating various data of gamification learning into gamification evaluation avoids simple artificial subjective evaluation, makes students' online learning evaluation more reflect students' online actual learning efforts, and alleviates the influence of emotional exhaustion and low sense of accomplishment on learning results. H5 does not hold because students, as adults, have relatively mature learning behavior. Compared with junior high school students and senior high school students, the correction effect of learning behavior misconduct is not obvious for students, and game evaluation has less impact on their misconduct. Therefore, gamification evaluation does not play an obvious mediating effect in the significant negative impact of misconduct on students' online learning performance.

Table 5. Mediating effect results

\begin{tabular}{|c|c|c|c|c|c|c|c|c|c|c|}
\hline Term & $\begin{array}{c}C \text { total } \\
\text { effect }\end{array}$ & $\mathbf{a}$ & b & $\begin{array}{c}\text { a }^{*} \text { Inter- } \\
\text { mediary } \\
\text { effect value }\end{array}$ & $\begin{array}{c}\mathbf{a}^{*} \mathbf{b} \\
(\text { Boot } \\
\text { SE) }\end{array}$ & $\begin{array}{l}a^{*} b(z) \\
\text { value })\end{array}$ & $\begin{array}{l}a^{*} b(z) \\
\text { value) }\end{array}$ & $\begin{array}{l}a^{*} b(95 \% \\
\text { Boot CI) }\end{array}$ & $\begin{array}{c}\text { c' direct } \\
\text { effect }\end{array}$ & $\begin{array}{c}\text { Test } \\
\text { results }\end{array}$ \\
\hline $\begin{array}{l}\text { Fac- } \\
\text { tor } 1=>\mathrm{Fa} \\
\text { ctor5 }=>\mathrm{F} \\
\text { actor4 }\end{array}$ & $\overline{-}^{-}$ & $0.591^{*}$ & $\underset{*}{-}$ & -0.372 & 0.006 & $\begin{array}{c}- \\
62.05 \\
6\end{array}$ & 0 & $\begin{array}{c}-0.501 \sim- \\
0.214\end{array}$ & -0.078 & $\begin{array}{l}\text { Complete } \\
\text { mediation }\end{array}$ \\
\hline $\begin{array}{l}\text { Fac- } \\
\text { tor } 2=>\mathrm{Fa} \\
\text { ctor5 }=>\mathrm{F} \\
\text { actor4 }\end{array}$ & $0.378^{* *}$ & -0.099 & $\underset{*}{-}$ & 0.063 & 0.005 & $\begin{array}{c}12.00 \\
9\end{array}$ & 0 & $\begin{array}{c}-0.067 \sim \\
0.176\end{array}$ & $0.316^{* *}$ & $\begin{array}{l}\text { Mediating } \\
\text { effect is not } \\
\text { significant. }\end{array}$ \\
\hline $\begin{array}{l}\text { Fac- } \\
\text { tor3 }=>\mathrm{Fa} \\
\text { ctor5 }=>\mathrm{F} \\
\text { actor4 }\end{array}$ & $\overline{-}^{-}$ & $0.196^{*}$ & $\underset{*}{-}{ }^{-}$ & -0.123 & 0.004 & $\begin{array}{c}- \\
29.59 \\
5\end{array}$ & 0 & $\begin{array}{c}-0.198 \sim- \\
0.003\end{array}$ & -0.17 & $\begin{array}{l}\text { Complete } \\
\text { mediation }\end{array}$ \\
\hline
\end{tabular}

\section{Conclusion}

The emergence of artificial intelligence, 5G technology, Internet of Things, and other emerging technologies has promoted the development of online learning. An increasing number of learners and teachers love and use the network to obtain and expand knowledge. However, the massive learning resources of online learning and the non-real-time interactive communication of teachers exacerbate the pressure of students on online learning. I also leads to students' negative attitudes toward online courses and studies, and it reduces their learning performance level. This study constructs a research model on the impact of students' online learning burnout on learning performance. The intermediary role of game evaluation in the impact of students' online learning burnout on learning performance is also analyzed. The results show 
Paper - Impact of Students' Online Learning Burnout on Learning Performance - the Intermediary...

that the Cronbach's $\alpha$ coefficient and the KMO value of the constructed questionnaire are 0.828 and 0.781 , respectively, which indicate that the reliability and validity of this study are very good. Emotional exhaustion, improper behavior, and low sense of accomplishment will significantly negatively affect the online learning performance of students. Game evaluation plays a role in stimulating students' online learning motivation, alleviating their online learning anxiety, reducing their online learning burnout, and improving their online learning performance. Further research should be made on the relationship between students' learning burnout and learning motivation, game-based teaching, and evaluation system data integration.

\section{Acknowledgements}

The study was supported by the Human resources and social security of Hebei Province in 2021, Topic name: Research on the cultivation of vocational core literacy of higher vocational students; Project number: JRSHZ-2021-02111.

\section{$7 \quad$ References}

[1] Maslow, A. H. A theory of human motivation. Psychological review, 1943, vol. 50(4), pp. 370.

[2] Werbach, K. Gamificación. Barcelona: Fundació Factor Humà, 2013.

[3] L. R., Y. L., W.Lanhua, Relationship between professional commitment and learning burnout of undergraduates and scales developing. Acta Psychologica Sinica, 2005, vol. 37(05), pp. 632.

[4] Gaines, J., \& Jermier, J. M. Emotional exhaustion in a high stress organization. Academy of Management journal, 1993, vol. 26(4), pp. 567-586. https://doi.org/10.5465/255907

[5] Shyman, E. Identifying predictors of emotional exhaustion among special education paraeducators: A preliminary investigation. Psychology in the Schools, 2010, vol. 47(8), pp. 828-841. https://doi.org/10.1002/pits. 20507

[6] Lee, Y. H., Kwon, H. H., \& Richards, K. A. R. Emotional intelligence, unpleasant emotions, emotional exhaustion, and job satisfaction in physical education teaching. Journal of Teaching in Physical Education, 2019, vol. 38(3), 262-270. https://doi.org/10.1123/jtpe. 2018-0177

[7] Hopman, J. A., Tick, N. T., van der Ende, J., Wubbels, T., Verhulst, F. C., Maras, A., \& van Lier, P. A. Special education teachers' relationships with students and self-efficacy moderate associations between classroom-level disruptive behaviors and emotional exhaustion. Teaching and Teacher Education, 2018, 75, pp. 21-30. https://doi.org/10.1016/ j.tate.2018.06.004

[8] Van den Berghe, L., Cardon, G., Aelterman, N., Tallir, I. B., Vansteenkiste, M., \& Haerens, L. Emotional exhaustion and motivation in physical education teachers: A variable-centered and person-centered approach. Journal of Teaching in Physical Education, 2013, vol. 32(3), pp. 305-320. https://doi.org/10.1123/jtpe.32.3.305

[9] R Richards, K. A., Washburn, N. S., \& Hemphill, M. A. Exploring the influence of perceived mattering, role stress, and emotional exhaustion on physical education teacher/coach job satisfaction. European Physical Education Review, 2019, vol. 25(2), pp. 389408. https://doi.org/10.1177/1356336x17741402 
Paper - Impact of Students' Online Learning Burnout on Learning Performance - the Intermediary...

[10] Basim, H. N., Begenirbas, M., \& Can Yalcin, R. Effects of Teacher Personalities on Emotional Exhaustion: Mediating Role of Emotional Labor. Educational Sciences: Theory and Practice, 2013, vol. 13(3), pp. 1488-1496.

[11] Lee, Y. H., Richards, K. A. R., \& Washburn, N. Mindfulness, resilience, emotional exhaustion, and turnover intention in secondary physical education teaching. European Review of Applied Psychology, 2021, vol. 71(6), pp. 100625. https://doi.org/10.1016/j.erap. 2021.100625

[12] Ansari, A., Pianta, R. C., Whittaker, J. V., Vitiello, V. E., \& Ruzek, E. A. Preschool Teachers' Emotional Exhaustion in Relation to Classroom Instruction and Teacher-child Interactions. Early Education and Development, 2020, pp. 1-14. https://doi.org/10.1080/ 10409289.2020 .1848301

[13] Platsidou, M. Trait emotional intelligence of Greek special education teachers in relation to burnout and job satisfaction. School psychology international, 2010, vol. 31(1), pp. 6076. https://doi.org/10.1177/0143034309360436

[14] Cothran, D. J., \& Kulinna, P. H. Students' reports of misbehavior in physical education. Research quarterly for exercise and sport, 2007, vol. 78(3), pp. 216-224. https://doi.org/10. $\underline{1080 / 02701367.2007 .10599419}$

[15] Cothran, D. J., Kulinna, P. H., \& Garrahy, D. A. Attributions for and consequences of student misbehavior. Physical Education and Sport Pedagogy, 2009, vol. 14(2), pp. 155-167. https://doi.org/10.1080/17408980701712148

[16] Finn, J. D., Fish, R. M., \& Scott, L. A. (2008). Educational sequelae of high school misbehavior. The Journal of Educational Research, 2008, vol. 101(5), pp. 259-274. https://doi. org/10.3200/joer.101.5.259-274

[17] Gregory, J. F. Three strikes and they're out: African American boys and American schools' responses to misbehavior. International Journal of Adolescence and Youth, 1997, vol. 7(1), pp. 25-34. https://doi.org/10.1080/02673843.1997.9747808

[18] Hsu, W. T., Li, H. H., \& Pan, Y. H. Student misbehavior in physical education: The role of $2 \times 2$ achievement goals and moral disengagement. Journal of sports science \& medicine, 2017, vol. 16(3), pp. 302.

[19] Özek, U. Hold back to move forward? Early grade retention and student misbehavior. Education Finance and Policy, 2015, vol. 10(3), pp. 350-377. https://doi.org/10.1162/edfp_a $\underline{00166}$

[20] Supaporn, S. High school students' perspectives about misbehavior. Physical Educator, 2000, vol. 57(3), pp. 124.

[21] Supaporn, S., Dodds, P., \& Griffin, L. An ecological analysis of middle school misbehavior through student and teacher perspectives. Journal of teaching in physical education, 2003, vol. 22(3), pp. 328-349. https://doi.org/10.1123/jtpe.22.3.328

[22] Glock, S., \& Kleen, H. Gender and student misbehavior: Evidence from implicit and explicit measures. Teaching and Teacher Education, 2017, vol. 67, pp. 93-103. https:// doi.org/10.1016/j.tate.2017.05.015

[23] Ratcliff, N. J., Jones, C. R., Costner, R. H., Savage-Davis, E., \& Hunt, G. H. The Elephant in the Classroom: The Impact of Misbehavior on Classroom Climate. Education, 2010, vol. 131(2), pp. 306-314.

[24] Ford, D. Y., \& Moore, J. L. Understanding and reversing underachievement, low achievement, and achievement gaps among high-ability African American males in urban school contexts. The urban review, 2013, vol. 45(4), pp. 399-415. https://doi.org/10.1007/s11256$\underline{013-0256-3}$

[25] Marks, G. N. Influences on, and the consequences of, low achievement. The Australian Educational Researcher, 2006, vol. 33(1), pp. 95-115. https://doi.org/10.1007/bf03246283 
Paper - Impact of Students' Online Learning Burnout on Learning Performance - the Intermediary...

[26] Lalley, J. P., \& Miller, R. H. Effects of Pre-Teaching and Re-Teaching on Math Achievement and Academic Self-Concept of Students with Low Achievement in Math. Education, 2006, vol. 126(4), pp. 747-755.

[27] Gilleece, L., Cosgrove, J., \& Sofroniou, N. Equity in mathematics and science outcomes: Characteristics associated with high and low achievement on PISA 2006 in Ireland. International Journal of Science and Mathematics Education, 2010, vol. 8(3), pp. 475-496. https://doi.org/10.1007/s10763-010-9199-2

[28] Wehby, G. L., Collett, B. R., Barron, S., Romitti, P., \& Ansley, T. Children with oral clefts are at greater risk for persistent low achievement in school than classmates. Archives of disease in childhood, 2015, vol. 100(12), pp. 1148-1154. https://doi.org/10.1136/archdis child-2015-308358

[29] Espinosa, R., \& Ochoa, A. Concentration of California Hispanic students in schools with low achievement: A research note. American Journal of Education, 1986, vol. 95(1), pp. 77-95. https://doi.org/10.1086/444293

[30] Merrell, K. W., Merz, J. M., Johnson, E. R., \& Ring, E. N. Social competence of students with mild handicaps and low achievement: A comparative study. School Psychology Review, 1992, vol. 21(1), pp. 125-137. https://doi.org/10.1080/02796015.1992.12085600

[31] Kingdon, G., \& Cassen, R. Ethnicity and low achievement in English schools. British Educational Research Journal, 2010, vol. 36(3), pp. 403-431. https://doi.org/10.1080/0141 $\underline{1920902989185}$

[32] Yu, W. F., She, H. C., \& Lee, Y. M. The effects of Web-based/non-Web-based problemsolving instruction and high/low achievement on students' problem-solving ability and biology achievement. Innovations in Education and Teaching International, 2010, vol. 47(2), pp. 187-199. https://doi.org/10.1080/14703291003718927

[33] Lu, S. J., Liu, Y. C., Chen, P. J., \& Hsieh, M. R. Evaluation of AR embedded physical puzzle game on students' learning achievement and motivation on elementary natural science. Interactive Learning Environments, 2020, vol. 28(4), 451-463. https://doi.org/10. $\underline{1080 / 10494820.2018 .1541908}$

[34] Hieftje, K., Pendergrass, T., Kyriakides, T. C., Gilliam, W., \& Fiellin, L. An evaluation of an educational video game on mathematics achievement in first grade students. Technologies, 2017, vol. 5(2), pp. 30. https://doi.org/10.3390/technologies5020030

[35] Kocadere, S. A., \& Çağlar, Ş. The design and implementation of a gamified assessment. Journal of e-Learning and Knowledge Society, 2015, vol. 11(3), pp. 1-8.

[36] Yildirim, I.The effects of gamification-based teaching practices on student achievement and students' attitudes toward lessons. The Internet and Higher Education, 2017, vol. 33, pp. 86-92. https://doi.org/10.1016/j.iheduc.2017.02.002

[37] Yıldırım, İ., \& Şen, S. The effects of gamification on students' academic achievement: A meta-analysis study. Interactive Learning Environments, 2019, pp. 1-18. https://doi.org/ $\underline{10.1080 / 10494820.2019 .1636089}$

[38] Leaning, M. A study of the use of games and gamification to enhance student engagement, experience and achievement on a theory-based course of an undergraduate media degree. Journal of Media Practice, 2015, vol. 16(2), pp. 155-170. https://doi.org/10.1080/ 14682753.2015 .1041807

[39] Dias, J. Teaching operations research to undergraduate management students: The role of gamification. The International Journal of Management Education, 2017, vol. 15(1), pp. 98-111. https://doi.org/10.1016/j.ijme.2017.01.002

[40] Göksün, D. O., \& Gürsoy, G. Comparing success and engagement in gamified learning experiences via Kahoot and Quizizz. Computers \& Education, 2019, vol. 135, pp. 15-29. https://doi.org/10.1016/j.compedu.2019.02.015 
Paper - Impact of Students' Online Learning Burnout on Learning Performance - the Intermediary...

\section{Authors}

Dandan Mu is an associate professor in Hebei Jiaotong Vocational and Technical College, Shijiazhuang, 050035, China.

Wei Guo is a Lecturer in Hebei Jiaotong Vocational and Technical College, Shijiazhuang, 050035, China.

Article submitted 2021-10-27. Resubmitted 2021-12-03. Final acceptance 2021-12-06. Final version published as submitted by the authors. 